\title{
Consumer-related factors influencing antidepressant adherence in unipolar depression: a qualitative study
}

This article was published in the following Dove Press journal: Patient Preference and Adherence

Pornchanok Srimongkon

Parisa Aslani

Timothy F Chen

The University of Sydney School of Pharmacy, Sydney, NSW, Australia
Correspondence: Pornchanok Srimongkon

The University of Sydney School of Pharmacy, Rm N507, Lv. 5. Pharmacy and Bank Building A I5, Science Road, Sydney, NSW 2006, Australia

Tel +6I 44976 I980

Email psri6621@uni.sydney.edu.au
Purpose: To explore factors which facilitate and negatively impact adherence, at initiation, implementation and discontinuation phases of adherence to antidepressant medicines.

Patients and methods: Semi-structured, face-to-face interviews were conducted with patients suffering from unipolar depression. The digitally audio-recorded and transcribed verbatim were used. Transcripts were thematically content analyzed and data managed using N-Vivo software.

Results: Twenty-three interviews were conducted. The predominant factors facilitating initiation of therapy included self-motivation and severity of depression. Factors aiding persistence with therapy included belief in, and effectiveness of, antidepressants. Stigma and fear of adverse events inhibited initiation of therapy, whilst adverse events and ineffectiveness of antidepressants contributed to discontinuation. Patients with strong perceptions of the necessity and few concerns about antidepressants were more likely to adhere to treatment at all phases of adherence.

Conclusion: Different factors influence medication adherence at the different phases of adherence. These factors were based on individual perceptions about depression and its treatment, and actual experiences of antidepressant treatment. This information should be considered by health care professionals in delivering targeted and tailored interventions to foster adherence. Strategies to address medication non-adherence in unipolar depression patients should consider the phase of adherence and individual perceptions about depression and its treatment, along with previous experiences with treatment for depression.

Keywords: depression, adherence, influencing factors, facilitators, barriers

\section{Introduction}

The most frequently cited definition of medication adherence, developed by the World Health Organization, is "the extent to which a person's behavior-taking medication, following a diet, and/or executing lifestyle changes, corresponds with agreed recommendations from a health care provider". ${ }^{1}$ More recently, medication adherence has been defined by a European consortium of researchers (ABC project: the Ascertaining Barriers for Compliance of medicines) as a continuous process, comprising three phases: initiation, implementation and discontinuation of therapy. ${ }^{2}$ Initiation occurs when the patient takes the first dose whilst discontinuation occurs when the patient stops taking the prescribed medication. Implementation of therapy refers to the actual dosing of medication consumption from initiation until the last dose. ${ }^{2}$

Globally, the total number of people living with depression was estimated to exceed 300 million in 2015 , equivalent to $4.4 \%$ of the world's population. ${ }^{3}$ This estimation increased by $18.4 \%$ between 2005 and $2015 .{ }^{3}$ Depression is ranked by the WHO as 
the single largest contributor to global disability and suicide deaths. ${ }^{3}$ However, medication adherence rates in depression are low. Approximately $30 \%$ of patients with depression do not complete their treatment. ${ }^{4}$ The average length of treatment in unipolar depression has been reported as $<6$ months, with $50 \%-60 \%$ discontinuation rates within the first $10-16$ weeks of treatment..$^{-7}$ In one study, only $20 \%$ of patients reported good adherence (adherence rate above $80 \%$ ) at 4 months after treatment initiation, ${ }^{5}$ while most treatment guidelines recommended continuation of antidepressant treatment for 6-9 months after recovery. ${ }^{8,9}$

Depression itself is a risk factor for non-adherence. ${ }^{10,11}$ A meta-analysis showed that medication non-adherence was three times higher in patients with depression compared to other conditions. ${ }^{11}$ Antidepressant non-adherence may lead to unnecessary switches in antidepressant medications, superfluous instructions to increase the dose, initiation of unwarranted adjuvant treatments, and misclassification of patients as treatment resistant. ${ }^{12}$ One study in the USA reported that $4.8 \%$ of patients did not initiate antidepressant treatment at 6 months after an antidepressant was prescribed, and $12.2 \%$ reported ceasing therapy within the first 6 months. ${ }^{13}$ The most important reason for those who did not commence antidepressants was concern about potential adverse drug reactions (ADRs), while the most important reason for ceasing antidepressant treatment was that the antidepressant was not helping. ${ }^{13}$ Other factors contributing to early discontinuation of antidepressant medicines include adverse effects, severity of illness, comorbidity, personality traits, and lack of support from health providers. ${ }^{14,15}$ Previous studies have shown that the symptoms of depression improving or becoming worse, the uncertainty about the usefulness of antidepressants, experience of side effects or adverse events, perceived stigma, peer pressure, adverse media stories, preexisting beliefs, difficulties with cost and the availability of care, and preference for other interventions, particularly counseling, are common reasons for individuals to stop taking antidepressant medicines. ${ }^{16-19}$ While some studies have shown that personal experiences with antidepressant medicines have a major impact on treatment continuation, such as belief in and acceptance of antidepressant medicines as a treatment option, acceptance of their condition, no side effects, fear of recurrence of symptoms of depression if antidepressant medicines are ceased, positive attitudes and interaction with doctors directly influence whether consumers take antidepressant medicines. ${ }^{19,20}$

Medication adherence is a continuous and dynamic process that can change over time and is an individual patient behavior which is complex and is simultaneously influenced by several factors. ${ }^{21,22}$ Moreover, non-adherence may occur more frequently during a particular phase of treatment. ${ }^{23}$ To maximize treatment outcomes, it is crucial to consider the potential factors influencing adherence at each phase of adherence. Although existing studies have discussed a range of factors influencing medication adherence, most of them have focused on the implementation and discontinuation phases ${ }^{16-20}$ or have not specified the phase(s) of adherence assessed. For this reason, a qualitative approach which focuses on the way people interpret their lived experiences ${ }^{24}$ was employed in this study. The aim of this study was therefore to explore the facilitators or positive influencing factors which promote medication adherence at three phases of adherence (ie, initiation, implementation, and discontinuation) in unipolar depression from patients' perspectives; and to explore the barriers or negative influencing factors which reduce medication adherence at all phases of adherence.

\section{Patients and methods}

This was a qualitative study which used a phenomenological approach, to explore individual lived experiences of antidepressant medicine taking (the phenomenon of interest) in consumers with unipolar depression who lived in the Sydney metropolitan area. This approach allowed for the collection of detailed self-reported information relating to individual attitudes and perceptions while also providing a basis for disclosure and comparison between responses. This study was approved by the Human Research Ethics Committee of the University of Sydney and has been reported in accordance with the consolidated criteria for reporting qualitative studies (COREQ32). ${ }^{25}$ The inform consent and relevant information had been given to the participants, therefore the consent form was signed prior to the commencement of an interview process.

\section{Study participants}

A purposive sample of consumers with unipolar depression was recruited to ensure mix of gender, age, duration of current and previous use of antidepressants. The inclusion criteria for this study were: 1 ) age $\geq 18$ years, 2) able to speak English fluently, without needing a translator, and 3) antidepressant medicine prescribed for unipolar depression currently or consumers who had ceased antidepressants in the 6 months prior to recruitment.

\section{Recruitment}

A three-pronged recruitment strategy was employed which included recruitment of participants from community 
pharmacies located within $15 \mathrm{~km}$ of the University of Sydney, through advertising on Internet websites and via a market research company. For the first strategy, 27 pharmacies were approached and 19 agreed to participate. Of those who did not participate, five did not respond and three refused to participate (one pharmacy did not have a policy to participate in research, one did not agree with the recruitment process and another did not give a reason). Participating community pharmacies displayed study advertisements and provided flyers to potential participants who were collecting a repeat prescription for an antidepressant for unipolar depression. Potential participants who were interested in taking part in the study were then directly contacted by the researchers via e-mail, text message, or phone.

\section{Interview guide}

A semi-structured interview guide was developed to address the specific study objectives. The interview guide was based on the $\mathrm{ABC}$ conceptual framework for adherence, published literature and the experience of research team members. Key topics included personal experiences of depression, previous experiences of taking antidepressants and side effects, effectiveness of antidepressants, support network, relationship with doctors and other health care professionals, stigma experienced, alcohol consumption, smoking behavior and lifestyle.

\section{Data collection}

Individual, face-to-face interviews were conducted. The interviews were digitally audio-recorded and transcribed verbatim. Participants fulfilling the inclusion criteria were interviewed by one of the researchers, P.S. $(n=16)$ or T.C. $(n=7)$. Participants gave written consent for interview recording and for publication of de-identified data. The study participants' names were replaced by a code number once the interviews were transcribed. The transcripts were also checked for accuracy against the original recordings by P.S. The interviews lasted between 20 and 69 minutes and were carried out between February and August 2015. Data analysis was performed during July 2015 to February 2016. Interviews were conducted until data saturation, ${ }^{26}$ which was reached at the 21 st participant. An additional two participants were interviewed to ensure that there were no further emergent themes.

\section{Data analysis}

Coding of the transcripts was carried out using iterative thematic analysis, with NVivo10 program for data management. The codes were extracted and grouped according to the themes and subthemes. ${ }^{24}$ Themes were derived from data extraction and grouped under the $\mathrm{ABC}$ framework for positive and negative factors at the three phases. Initial coding was performed by the first author (P.S.). Findings were cross checked by the other two investigators, experienced in qualitative data analyses.

\section{Results}

Twenty-three participants were recruited. Of these participants, eight were recruited from community pharmacies, and 15 were recruited via a market research company. No participants were recruited via online advertising. No data on the response rate for participants recruited by the market research company or through community pharmacies were available. Participant characteristics and the current use of antidepressant medicines are presented in Table 1.

This research focused on patient-related factors, derived from their actual experiences, which were reported to influence medication adherence, from initiation to discontinuation. The results obtained related to the first antidepressant

Table I Characteristics of the participants $(n=23)$

\begin{tabular}{|c|c|}
\hline Characteristics & $\mathbf{N}$ \\
\hline \multicolumn{2}{|l|}{ Demographic data } \\
\hline \multicolumn{2}{|l|}{ Age range (years): 19-63, median: 37, mean: 40} \\
\hline Gender: females/males & $15 / 8$ \\
\hline \multicolumn{2}{|l|}{ Self-report ethnic group } \\
\hline - Oceania (Australia or New Zealand) & 16 \\
\hline - Others (Americas, South-East Asia, North- & 7 \\
\hline \multicolumn{2}{|l|}{ West Europe, South African, Southern and } \\
\hline \multicolumn{2}{|l|}{ Eastern Europe) } \\
\hline \multicolumn{2}{|l|}{ Living circumstances } \\
\hline - Living with partner or family & 10 \\
\hline - Living with roommate/housemate & 5 \\
\hline - Living alone & 8 \\
\hline \multicolumn{2}{|l|}{ Highest level of education completed } \\
\hline - Secondary & 6 \\
\hline - Diploma & 3 \\
\hline - Bachelor & 9 \\
\hline - Postgraduate & 3 \\
\hline - Other* & 2 \\
\hline Prescription of antidepressant: $<5 / \geq 5$ years & $13 / 10$ \\
\hline \multicolumn{2}{|l|}{ Current antidepressant medicines prescribed } \\
\hline $\begin{array}{l}\text { SSRIs: citalopram, escitalopram, fluoxetine, } \\
\text { paroxetine, sertraline }\end{array}$ & 9 \\
\hline SNRIs: desvenlafaxine, duloxetine, venlafaxine & 7 \\
\hline TCA: amitriptyline & I \\
\hline Others: mirtazapine, phenelzine, reboxetine & 3 \\
\hline \multirow{2}{*}{\multicolumn{2}{|c|}{$\begin{array}{l}\text { Most recently ceased antidepressant medicines } \\
\text { prescribed }\end{array}$}} \\
\hline & \\
\hline SSRIs: escitalopram, sertraline & 3 \\
\hline
\end{tabular}

Note: *Primary school, certificate.

Abbreviations: SSRI, selective serotonin reuptake inhibitors; SNRI, serotoninnorepinephrine reuptake inhibitors; TCA, tricyclic antidepressants. 
ever prescribed through to the most recent one for the participant. Most participants had tried a range of different antidepressant medicines over a period of time in order to find the "right one". A few participants had recently ceased taking their antidepressant medicine or reported intermittent consumption. Some of those who had ceased their antidepressant medicine were looking for an affordable and effective medicine with less or no ADRs. The majority of participants had chronic depression, and so had experience of restarting new treatment cycles with different antidepressant medicines. Some participants tried to cease their antidepressant medicines to see if they could cope without them. Most participants realized the need for antidepressant medicines in order to boost their mood and day-to-day function.

At initiation, participants were more likely to commence antidepressants once they accepted that their depression was real and if they valued antidepressant treatment. Belief in and awareness about the need for antidepressants, as well as positive treatment effects, encouraged participants to adhere to antidepressant medicines. Although, fear of possible ADRs was not common, it was a strong barrier at initiation. Unpleasant ADRs, unsatisfactory treatment outcomes and depressive symptoms were common barriers which led to discontinuation of treatment. The index of the terms used in this study, in relation to influencing factors is shown in Table S1.

\section{Positive factors}

A broad range of positive influencing factors at the three phases of adherence were identified. Self-motivation; selfmanagement; and belief in and awareness about the need for, the importance of, and the effectiveness of antidepressant medicines were main facilitators reported at all phases. At initiation, the predominant factors were self-motivation, patient perception that depressive symptoms were real and manageable, and willingness to follow doctor's order. During the implementation phase, positive effect of antidepressant treatment with minimal ADRs experienced, and the ability to self-manage were reported as the main facilitators. To prevent discontinuation of therapy, positive influencing factors included self-motivation and belief in antidepressant therapy. Figure 1 shows a schematic representation of positive factors reported to influence medication adherence at all phases.

\section{Positive factors at initiation of therapy}

Multiple factors were reported to encourage medication adherence at initiation: self-motivation, the acceptance of depression diagnosis, willingness to follow doctor's orders, the severity of depressive symptoms, and recognition of antidepressant medicines. The majority of participants revealed that they wanted to feel better. Some participants wanted to be "cured" or "feel like normal" and that was the main factor that motivated them to commence antidepressant therapy

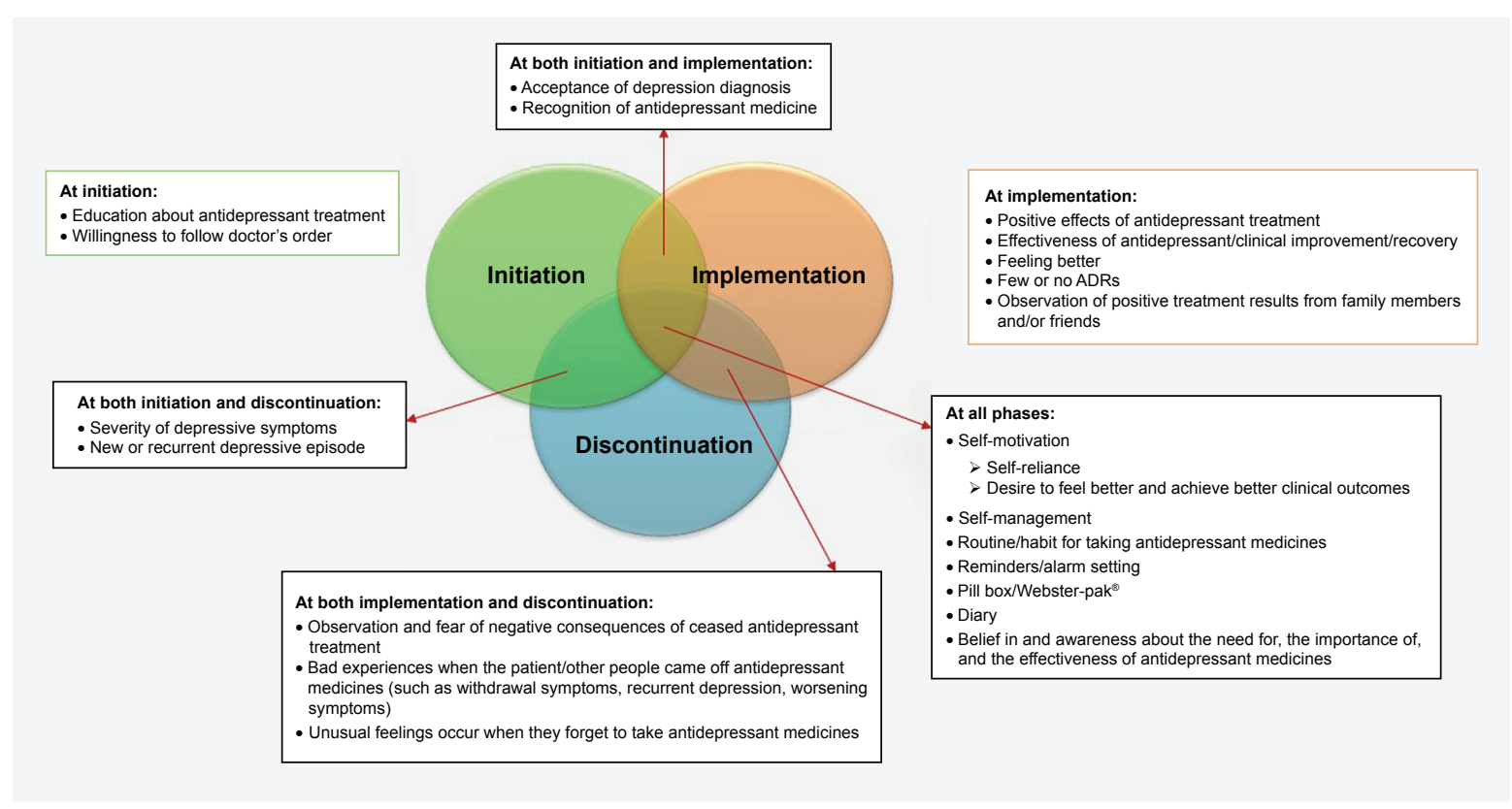

Figure I Factors which positively influenced medication adherence at the three phases of adherence: initiation, implementation, and discontinuation of therapy. Abbreviation: ADRs, adverse drug reactions. 
(quote no 1, Table 2). Once participants realized that they were experiencing depressive symptoms, they were more likely to start an antidepressant. When patients believed in and valued antidepressant medicines, they were more likely to take them regularly. Some participants mentioned that the severity of depressive symptoms compelled them to commence antidepressants. More severe depressive symptoms provided a greater motivation to commence the treatment. However, in a few cases when patients were too ill to make a critical decision about their treatment, they relied more on their doctor rather than their own decision. Some participants indicated that they believed in their doctor's judgment, and therefore followed their doctor's advice.

Most participants suggested a variety of strategies which might encourage adherence to antidepressants such as early detection of depression and providing more education about the value of antidepressant medicines to target population.

\section{Positive factors at implementation of therapy}

A range of predominant factors were identified as positively influencing adherence at the implementation phase: positive effect of antidepressant therapy, belief in and realizing the need for antidepressant medicines, self-management, and fear of the effects if antidepressant therapy is ceased. The majority of participants reported that positive effects of antidepressant treatment, particularly the effectiveness of antidepressant medicines was the main reason to adhere to antidepressants. Participants were likely to continue their antidepressant medicine if depressive symptoms were lessened with few or no undesirable ADRs.

Self-management was a predominant positive factor for the majority of participants for persisting with therapy. A number of participants revealed that once they realized the importance of antidepressant therapy and believed in them, they organized a routine for taking their medicine regularly. The majority of participants reported a variety of techniques that they used to remind themselves to take their antidepressant regularly, for example, using a pill box, or setting an alarm (on their phone), putting their antidepressant medicine in a noticeable spot (such as next to the coffee maker or on a bedside table), choosing a regular time to take their antidepressant (such as the first thing to do in the morning, after breakfast, or before going to bed). In one case, a participant used a diary to remind herself to take her antidepressant routinely. Self-management was also important at this phase. Some participants indicated that they believed

Table 2 Indicative quotes of positive and negative factors influencing the three phases of adherence

\begin{tabular}{|c|c|c|}
\hline Factors & Themes & Quotes \\
\hline \multirow[t]{3}{*}{ Positive } & Self-motivation & $\begin{array}{l}\text { I. [I wanted] to lessen some of the symptoms that I had [...] I was down, really down and } \\
\text { upset [No } 9 / M / 30 \mathrm{Y} \text {; Adherence phase: I/P/D] } \\
\text { 2. I'll just keep going down and down and down until I feel l've got to get back up again. } \\
\text { I'll start that [antidepressant] again. [No 5/F/57 Y; Adherence phase: I/P/D] }\end{array}$ \\
\hline & $\begin{array}{l}\text { Fear of negative consequences of } \\
\text { ceased antidepressant medicines }\end{array}$ & $\begin{array}{l}\text { 3. It took nearly a week [for them] to work and since then l've had a fear of stopping them } \\
\text { so I've never really done it because I am too scared to stop and get those feelings back. } \\
\text { [No 20/F/53 Y; Adherence phase: P/D] }\end{array}$ \\
\hline & $\begin{array}{l}\text { Belief in and the effectiveness of } \\
\text { antidepressant medicines }\end{array}$ & $\begin{array}{l}\text { 4. I'm a little bit doubtful, but, [...] l've seen medication [used] in family and friends, and } \\
\text { I've seen it work. [No I5/M/44 Y; Adherence phase: I/P/D] }\end{array}$ \\
\hline \multirow[t]{6}{*}{ Negative } & Fear of anticipated ADRs & $\begin{array}{l}\text { 5. I was really worried about weight gain and I didn't want to take medication that would } \\
\text { make me gain weight. [No } 22 / \mathrm{F} / 28 \mathrm{Y} \text {; Adherence phase: I] }\end{array}$ \\
\hline & Self-stigma & $\begin{array}{l}\text { 6. I really didn't want to [take them] in the beginning. I think it's just }[. . .] \text { embarrassing }[. . .] \\
\text { I felt like there's something wrong with me }[\ldots] \text { [but] I could just talk myself into being } \\
\text { happy instead of having to take it. [No } 22 / F / 28 \text { Y; Adherence phase: I/P/D] }\end{array}$ \\
\hline & Experiencing unpleasant ADRs & $\begin{array}{l}\text { 7. The Avanza }{ }^{\circledR} \text { [mirtazapine], it was prescribed to me, I was in a pretty difficult position } \\
\text { and with Avanza it helps you sleep but I didn't like it because I stacked on the weight } \\
\text { [No 2I/M/45 Y; Adherence phase: I/P/D] }\end{array}$ \\
\hline & Economic issue & $\begin{array}{l}\text { 8. The newest one that I tried which I went off was Valdoxan }{ }^{\circledR} \text { [agomelatine] because it } \\
\text { was so expensive [No } 5 / F / 57 \text { Y; Adherence phase: P] }\end{array}$ \\
\hline & Forgetfulness & $\begin{array}{l}\text { 9. First thing I'll do is just put that [antidepressant] in my hand and take it. I made the } \\
\text { mistake of putting my tablet two days ago into my dressing gown pocket, and that's } \\
\text { where it stayed. I found it the next day. Forgetfulness is also a symptom of depression } \\
\text { and I find that I do suffer [No I9/F/60 Y; Adherence phase: P] }\end{array}$ \\
\hline & $\begin{array}{l}\text { Previous negative experiences of } \\
\text { antidepressant medicines }\end{array}$ & $\begin{array}{l}\text { 10. When I read the symptoms or side effects of it, I thought, yeah, I've had this before. } \\
\text { I'm not going on it. [No I8/M/28 Y; Adherence phase: D] }\end{array}$ \\
\hline
\end{tabular}

Abbreviations: $M$, male; F, female; $Y$, years old; I, initiation; $P$, implementation; $D$, discontinuation. 
in antidepressant medicines, and trusted and were willing to follow doctor's order.

Some participants stated that they feared the effect if they ceased their antidepressant medicine, as they had previously had experienced or heard about negative outcomes in other people (quote no 3, Table 2). Some participants observed positive results of antidepressant treatment from other people, which effectively motivated them to continue therapy.

A few participants mentioned that they wanted better health outcomes and so this motivated them to continue their antidepressant medicine. Two participants revealed unusual feelings when they missed a dose (one explained an electric shock-like feeling, another one reported a "zapping" sensation), and this reminded them to continue to take their medicine.

Comorbidity can affect medication adherence in different ways. One participant had depression along with chronic pain, and was willing to take antidepressant medicines regularly, because they relieved both conditions. While another participant reported some difficulties in adherence to antidepressant medicines because of attention deficit hyperactivity disorder.

Most participants realized the benefits of commencing and maintaining some activities or lifestyles that improved depressive symptoms such as meditation, gentle exercise, hobbies and social activities. In a few cases, although participants stated that they believed more in alternative treatments such as acupuncture or herbal medicines, they decided to stay on antidepressant treatment.

\section{Positive factors at discontinuation of therapy}

The discontinuation phase of adherence occurred when an individual stopped taking their antidepressant medicine of their own accord. Unlike initiation and implementation, which are "positive" behaviors, discontinuation is a "negative" behavior. Therefore, in contrast to initiation and implementation, positive factors contribute to discontinuation, whilst negative factors stop discontinuation. Hence, positive factors at this phase were similar to negative factors at the implementation phase.

\section{Negative factors}

Participants reported a wide range of factors that could adversely influence adherence to antidepressant medicines, at all phases of adherence. This included stigma associated with the use of antidepressant medicines, experiencing or anticipating ADRs, and personal issues such as not believing in the effectiveness of antidepressant treatment and unwilling to rely on medicine. At initiation, negative factors were mainly related to fear of or anticipating ADRs and self-stigma. At implementation, experiencing ADRs and ineffective treatment played a significant part in negatively influencing adherence. Other negative factors included forgetfulness, feeling better, and the existence of depressive symptoms. At the discontinuation phase, previous negative experiences with taking antidepressant medicines led to discontinuation of therapy and failure to start a new cycle of antidepressant therapy. Figure 2 shows a schematic representation of negative factors reported to influence medication adherence.

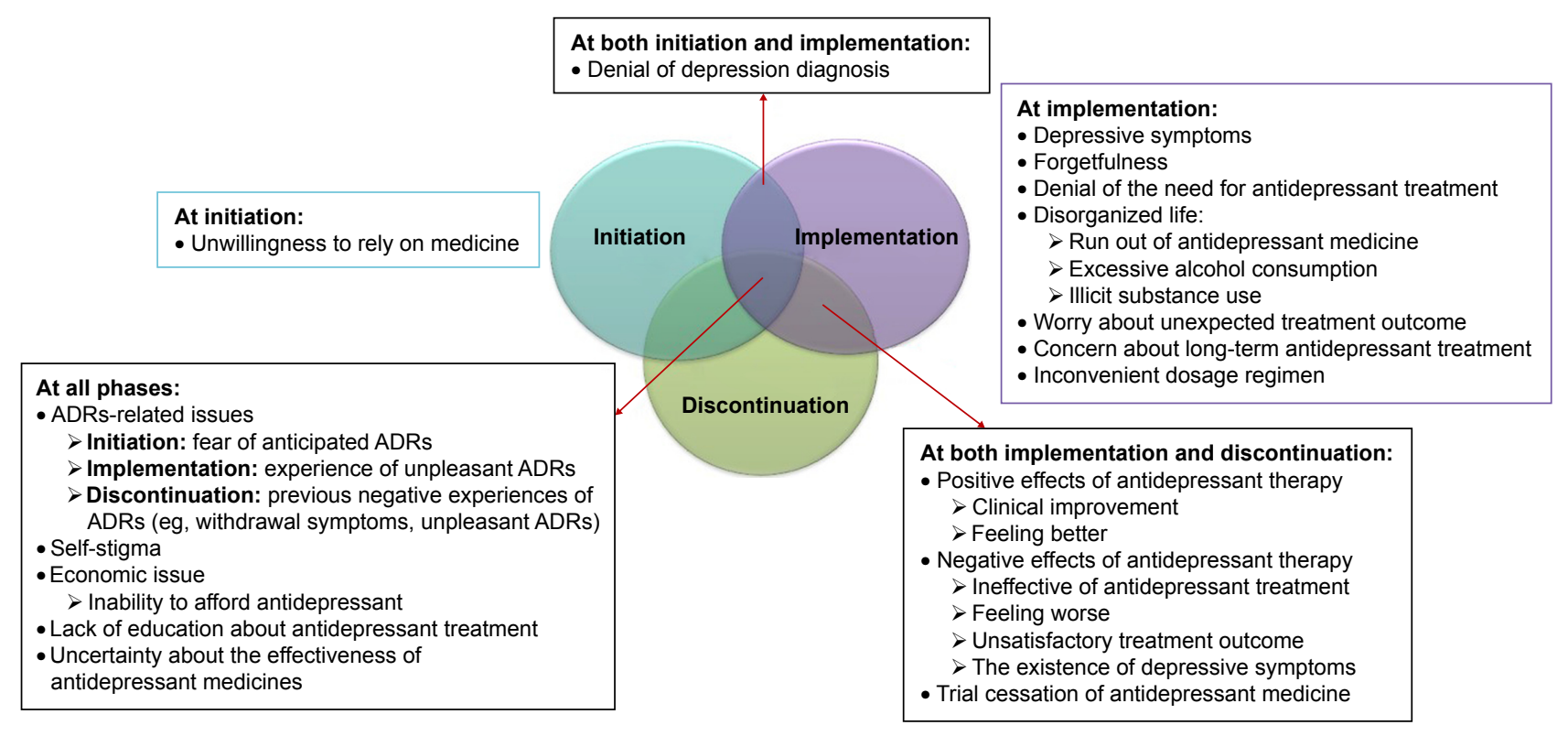

Figure 2 Factors which negatively influence medication adherence at the three phases of adherence: initiation, implementation, and discontinuation of therapy. Abbreviation: ADRs, adverse drug reactions. 


\section{Negative factors at initiation of therapy}

A number of factors were identified: unwillingness to rely on medicine, denial of depression diagnosis, fear of anticipated ADRs (eg, concern about weight gain) and self-stigma (eg, the feeling of being embarrassed when getting their prescription dispensed). Two participants reported that they did not want to rely on medicines, another one identified herself as an "anti-medication" type person, and one participant indicated lack of support from family, which resulted in delayed initiating antidepressant therapy. Two participants who revealed the hesitation to commence an antidepressant at the initial diagnosis, hence the initiation phase was delayed, and later, they reported experiencing recurrent episodes of depression. However, most of them were on their antidepressant at the time of interview.

\section{Negative factors at implementation of therapy}

A range of negative factors were identified: experiencing unpleasant ADRs, ineffectiveness of antidepressant medicines, uncertainty about the effectiveness of antidepressant medicines, forgetfulness, clinical improvement in depressive symptoms, and having depressive symptoms. These factors meant that participants did not persist with antidepressant therapy and this sometimes led to discontinuation of antidepressant medicines. In most cases, unpleasant ADRs and the ineffectiveness of antidepressant treatment were mentioned as reasons for not persisting with antidepressant medicines. Some participants mentioned that after they started to feel better, they were more likely to discontinue their antidepressant medicine. Depressive symptoms such as forgetfulness, lethargy and laziness were reported in some cases as negative influencing factors, which interfered with medication taking behavior. A few participants doubted the effectiveness of antidepressant treatment and conducted their own trials to cease their medicine to see how they would be without it. In some cases, excessive alcohol consumption and illicit drug use interfered with adherence to antidepressant therapy. A few participants revealed that they denied both their diagnosis of depression and the necessity of antidepressant treatment. In other cases, self-stigma, inability to afford antidepressant medicines, concern about long-term effects of taking antidepressant medicines, an inconvenient dosage regimen, and lack of education about antidepressant medicines were noted as negative factors which adversely influenced medication adherence.

\section{Negative factors at discontinuation of therapy}

As described above, discontinuation is a "negative" behavior. Therefore, negative factors at discontinuation stop discontinuation of antidepressant therapy.

\section{Discussion}

The results of this study are based on participants' selfreported actual experiences of antidepressant treatment as well as their perceptions and beliefs towards the use of antidepressant medicines for unipolar depression. This study comprehensively discussed factors influencing antidepressant adherence, and was able to capture information about facilitators of, and barriers to, antidepressant adherence at the three phases of medication taking (initiation, implementation, and discontinuation). Although there have been previous qualitative studies investigating medication adherence, this study is different because it uses the conceptual framework provided by the $\mathrm{ABC}$ consortium to allow for a more comprehensive analysis. This study therefore has the potential to inform tailored-interventions, based on the phase of adherence, for people prescribed antidepressant medicines.

The findings emphasized that consumers traded off the pros and cons of taking antidepressant medicines from initiation to discontinuation of therapy, based on the integration of their own experiences, beliefs about their health conditions and perceptions of antidepressant treatment effectiveness, observing the experiences of other consumers taking antidepressants, specifically close family and friends, and concerns about the ability to afford antidepressant treatment, before making their own decision. ${ }^{20}$ Similarly, Schofield et al have reported that patients learn to trade off the risks and benefits of antidepressant treatment based on trial and error. ${ }^{16}$ The majority of participants who continued antidepressant treatment in this study acknowledged the advantages of the treatment over the disadvantages, although some were burdened by their experiences with ADRs. ${ }^{27}$ In line with the Necessity-Concerns Framework, ${ }^{20,28-34}$ higher adherence rates were also reported by participants when they held stronger beliefs of the necessity of treatment than they did for concerns about treatment. ${ }^{28,35}$

Although participants identified a range of strategies that helped their medication adherence, it is noteworthy that the factors which may influence medication adherence in people with depression are likely to be both condition and medicine-related. For some, depressive symptoms drove participants to seek help and commence antidepressant medicines. Thompson et al also found that increasing depressive symptoms prompted participants with depressive symptoms to seek help. ${ }^{36}$ Once participants had decided to seek help, they could participate in the decision-making process by weighing up the necessity to take the antidepressant medicines against their concerns of taking them. ${ }^{17,37}$

At initiation, personal attitude and acknowledgement of their depressive condition and belief in antidepressant medicines were key factors facilitating medication 
adherence. ${ }^{38}$ Conversely, a negative attitude toward their depressive condition and lack of belief in antidepressant medicines inhibited medication adherence. ${ }^{39}$ Previous studies have also indicated that knowledge about disease and treatment combined with faith in the doctor motivates patients to start using medicines. ${ }^{39,40}$ Hence, strategies which may aid medication adherence in people recently diagnosed with depression and prescribed antidepressant medicines should include and emphasize, at the outset, education about depression and antidepressant treatment at the early stage. ${ }^{36}$ This process should also include accurate and consistent information from health care professionals, including the pros and cons of antidepressant treatment. Specifically, education should include discussion about the condition itself (depression) as well as the use of antidepressant medications. Participants indicated that the symptoms of depression such as constantly feeling sad, forgetfulness, loss of motivation, or a sense of hopelessness, may themselves inhibit adherence, such as delaying the initiation of treatment, or reducing motivation to persist with antidepressant medicines once prescribed. ${ }^{12,23}$ Hence education about depressive symptoms and their impact on daily activities was important. In terms of specific education about the use of medicines, participants reported the need for specific counseling on the delayed onset of antidepressant medicine effects and anticipated short and long-term ADRs especially at initiation of therapy. ${ }^{12,23}$ It is noteworthy that fear of anticipated ADRs, unwillingness to rely on medicines, and uncertainty about the effectiveness of antidepressant medicines could delay the initiation of therapy. Although only some had a fear of anticipated ADRs, this fear played a strong role in delaying the commencement of antidepressant medications.

Once the treatment was initiated, participants reported constantly balancing the positive and the negative impact of taking antidepressant medicines. If the benefit outweighed the harm, most participants were motivated to remain adherent. For example, when they felt better (clinical improvement) and/or believed in and perceived the need for antidepressant treatment over unpleasant ADRs and stigma. In contrast, when harm exceeded the perceived or actual benefit, they became non-adherent. If negative factors significantly outweighed the positive factors, such as the unbearable ADRs and unsatisfactory treatment outcome, they would consider ceasing or having a break in therapy.

Treatment efficacy, belief, and perceptions about the antidepressant were major influencing factors during the implementation phase of adherence. Belief in and perceived need for medications have been previously linked to medication adherence. ${ }^{31,41}$ Similarly, Ho et al have also found that clinical improvement was the major reason for patients to adhere to antidepressant treatment. ${ }^{42}$ Although positive effects of antidepressant therapy was one of the most powerful facilitators, paradoxically it also led to discontinuation, in some cases, as individuals felt they no longer needed treatment, as they were "better". ${ }^{17,43}$ From a different perspective, fear of the effect when ceasing an antidepressant medicine was a major facilitator for persisting with treatment. In contrast, ineffectiveness of antidepressant treatment and experiencing unpleasant ADRs, specifically sexual dysfunction, have been previously identified as the major barriers leading to discontinuation. ${ }^{13,20,44-48}$ Our study findings were therefore in line with previous findings which have also reported that perceived potential harmfulness (concerns) were significantly related to prior experience of ADRs. ${ }^{31,41}$

At discontinuation, new or recurrent depressive episodes prompted the majority of participants to seek out and commence the new treatment cycle of antidepressant medicines. In some cases, unsatisfactory treatment outcome and experiencing ADRs meant that consumers preferred alternative treatments (to antidepressants) such as acupuncture, herbal remedies, and counseling.

Many factors facilitated adherence at more than one phase. These included self-motivation, medication self-management for antidepressants, and trust in the doctor, whilst troublesome ADRs, self-stigma, and economic issues were significant barriers from initiation to discontinuation of therapy. Most of them were considered as modifiable factors (eg, attitudes, perceptions, beliefs about effectiveness of depression treatment, patient/provider communication, including stigma). ${ }^{49}$ Although, stigma was reported as a well-known barrier, $23,38,50,51$ we found that it was manageable once the consumer realized the need of antidepressant treatment. ${ }^{13}$

\section{Strengths}

Our research design specifically focused on the different phases of adherence to medicines (ie, initiation, implementation, and discontinuation) using the ABC framework. It comprehensively covered both facilitators of and barriers to medication adherence at these different phases. In taking this approach, we gained important insights into consumer perspectives, which are often overlooked by health care professionals. The recruitment process resulted in a wide range of experiences of depression and antidepressant treatment, duration of antidepressant treatment, age and background which likely reflects many consumers prescribed antidepressant treatment for depression management. 


\section{Limitations}

A relatively small number of participants was included in this study, as is the case with all qualitative studies. However, the sample size allowed us to reach theme saturation. Also, the participants in this study may not be representative of all people with unipolar depression. Specifically, all participants in this study acknowledged, recognized and had lived experience of depression. However, our study did not or could not include individuals (or groups) who do not acknowledge depression as a condition, and consequently the place of antidepressant medicines for the management of depression. Additionally, our initial recruitment approach of identifying consumers with depression through community pharmacy was low. Recruitment of participants for in-depth interviews about a potentially sensitive topic is challenging. Specifically for this study, the stigma associated with depression, ${ }^{52}$ in both consumers and society, may have contributed to the recruitment process. Hence, we added an alternative method of recruitment via a market research company to identify consumers.

\section{Directions for future research}

Since medication adherence is a multidimensional and complicated process, numerous factors typically affect the use of antidepressant medicines among people with unipolar depression. More specific aspects should be further explored such as antidepressant class-specific factors, and cultural-related factors in future studies.

\section{Conclusion}

Different factors influence medication adherence at the different phases of adherence. These factors were based on individual perceptions about depression and its treatment, and actual experiences of antidepressant treatment. This information should be considered by health care professionals when advising patients about adherence to antidepressant medicines, at the different phases of adherence, to ensure that targeted and tailored interventions are delivered to facilitate medication-taking behavior.

In order to optimize the use of antidepressant medicines, health care professionals should consider both positive and negative influencing factors at the different phases of adherence. To facilitate medication adherence, health care professionals should facilitate and encourage tailored use of positive influencing factors, and similarly address the negative influencing factors, at each of the phases of adherence. This approach is (more) likely to enhance treatment outcomes in people living with unipolar depression.

\section{Acknowledgment}

The authors thank the participants for their contribution to the study.

\section{Disclosure}

The authors report no conflicts of interest in this work.

\section{References}

1. World Health Organization (WHO). Adherence to Long-term Therapies. Geneva: WHO; 2003.

2. Vrijens B, de Geest S, Hughes DA, et al. A new taxonomy for describing and defining adherence to medications. Br J Clin Pharmacol. 2012; 73(5):691-705.

3. World Health Organization (WHO). Depression and Other Common Mental Disorders: Global Health Estimates. Vol. 041117. Geneva: WHO; 2017. Available from: http://apps.who.int/iris/ bitstream/10665/254610/1/WHO-MSD-MER-2017.2-eng.pdf?ua=1

4. Demyttenaere K. Risk factors and predictors of compliance in depression. Eur Neuropsychopharmacol. 2003;13(Suppl 3):69-75.

5. Serna MC, Cruz I, Real J, Gascó E, Galván L. Duration and adherence of antidepressant treatment (2003 to 2007) based on prescription database. Eur Psychiatry. 2010;25(4):206-213.

6. Ten Doesschate MC, Bockting CL, Schene AH. Adherence to continuation and maintenance antidepressant use in recurrent depression. J Affect Disord. 2009;115(1-2):167-170.

7. Sansone RA, Sansone LA. Antidepressant adherence: are patients taking their medications? Innov Clin Neurosci. 2012;9(5-6):41-46.

8. Gelenberg AJ, Freeman MP, Markowitz JC, et al. Practice Guideline for the Treatment of Patients with Major Depressive Disorder. Arlington, VA: American Psychiatric Association; 2010.

9. Armstrong C. APA releases guideline on treatment of patients with major depressive disorder. Am Fam Physician. 2011;83(10):1219.

10. Vlasnik JJ, Aliotta SL, Delor B. Medication adherence: factors influencing compliance with prescribed medication plans. Case Manager. 2005;16(2):47-51.

11. Dimatteo MR, Lepper HS, Croghan TW. Depression is a risk factor for noncompliance with medical treatment: meta-analysis of the effects of anxiety and depression on patient adherence. Arch Intern Med. 2000; 160(14):2101-2107.

12. Olfson M. Bringing antidepressant self-discontinuation into view. Psychiatr Serv. 2015;66(5):449.

13. Fortney JC, Pyne JM, Edlund MJ, et al. Reasons for antidepressant nonadherence among veterans treated in primary care clinics. $J$ Clin Psychiatry. 2011;72(6):827-834.

14. Hansen DG, Vach W, Rosholm JU, Søndergaard J, Gram LF, Kragstrup J. Early discontinuation of antidepressants in general practice: association with patient and prescriber characteristics. Fam Pract. 2004;21(6): 623-629.

15. Hung CI. Factors predicting adherence to antidepressant treatment Curr Opin Psychiatry. 2014;27(5):344-349.

16. Schofield P, Crosland A, Waheed W, et al. Patients' views of antidepressants: from first experiences to becoming expert. Br J Gen Pract. 2011;61(585):142-148

17. Jaffray M, Cardy AH, Reid IC, Cameron IM. Why do patients discontinue antidepressant therapy early? A qualitative study. Eur J Gen Pract. 2014;20(3):167-173.

18. Badger F, Nolan P. Concordance with antidepressant medication in primary care. Nurs Stand. 2006;20(52):35-40.

19. Grime J, Pollock K. Patients' ambivalence about taking antidepressants: a qualitative study. Pharm J. 2003;271(7270):516-519.

20. Anderson C, Roy T. Patient experiences of taking antidepressants for depression: a secondary qualitative analysis. Res Social Adm Pharm. 2013; 9(6):884-902. 
21. World Health Organization (WHO). Adherence to Long-Term Therapies: Evidence for Action. Geneva: WHO; 2003.

22. Brown MT, Bussell JK. Medication adherence: WHO cares? Mayo Clin Proc. 2011;86(4):304-314.

23. Bucci KK, Possidente CJ, Talbot KA. Strategies to improve medication adherence in patients with depression. Am J Health Syst Pharm. 2003;60(24):2601-2605.

24. Green J, Thorogood N. Qualitative Methods for Health Research. Great Britain: SAGE; 2009.

25. Tong A, Sainsbury P, Craig J. Consolidated criteria for reporting qualitative research (COREQ): a 32-item checklist for interviews and focus groups. Int J Qual Health Care. 2007;19(6):349-357.

26. Bowen GA. Naturalistic inquiry and the saturation concept: a research note. Qual Res. 2008;8(1):137-152.

27. Mohammed MA, Moles RJ, Chen TF. Medication-related burden and patients' lived experience with medicine: a systematic review and metasynthesis of qualitative studies. BMJ Open. 2016;6(2):e010035.

28. Horne R, Chapman SC, Parham R, Freemantle N, Forbes A, Cooper V. Understanding patients' adherence-related beliefs about medicines prescribed for long-term conditions: a meta-analytic review of the Necessity-Concerns Framework. PLoS One. 2013;8(12):e80633.

29. Tibaldi G, Clatworthy J, Torchio E, Argentero P, Munizza C, Horne R. The utility of the Necessity-Concerns Framework in explaining treatment non-adherence in four chronic illness groups in Italy. Chronic Illn. 2009;5(2):129-133.

30. Clifford S, Barber N, Horne R. Understanding different beliefs held by adherers, unintentional nonadherers, and intentional nonadherers: application of the Necessity-Concerns Framework. J Psychosom Res. 2008;64(1):41-46.

31. Aikens JE, Klinkman MS. Changes in patients' beliefs about their antidepressant during the acute phase of depression treatment. Gen Hosp Psychiatry. 2012;34(3):221-226.

32. Foot H, La Caze A, Gujral G, Cottrell N. The necessity-concerns framework predicts adherence to medication in multiple illness conditions: A meta-analysis. Patient Educ Couns. 2016;99(5):706-717.

33. Al Jumah K, Hassali MA, Al Qhatani D, El Tahir K. Factors associated with adherence to medication among depressed patients from Saudi Arabia: a cross-sectional study. Neuropsychiatr Dis Treat. 2014;10:2031-2037.

34. de Las Cuevas C, Peñate W, Sanz EJ. Risk factors for non-adherence to antidepressant treatment in patients with mood disorders. Eur J Clin Pharmacol. 2014;70(1):89-98.

35. Aikens JE, Nease DE, Nau DP, Klinkman MS, Schwenk TL. Adherence to maintenance-phase antidepressant medication as a function of patient beliefs about medication. Ann Fam Med. 2005;3(1):23-30.

36. Thompson A, Hunt C, Issakidis C. Why wait? Reasons for delay and prompts to seek help for mental health problems in an Australian clinical sample. Soc Psychiatry Psychiatr Epidemiol. 2004;39(10):810-817.

37. Gibson K, Cartwright C, Read J. Patient-centered perspectives on antidepressant use. Int J Ment Health. 2014;43(1):81-99.
38. Garfield S, Smith F, Francis S-A. The paradoxical role of antidepressant medication - returning to normal functioning while losing the sense of being normal. J Ment Health. 2003;12(5):521-535.

39. Anderson C, Kirkpatrick S, Ridge D, Kokanovic R, Tanner C. Starting antidepressant use: a qualitative synthesis of UK and Australian data. BMJ Open. 2015;5(12):e008636.

40. Dowell J, Hudson H. A qualitative study of medication-taking behaviour in primary care. Fam Pract. 1997;14(5):369-375.

41. Brown C, Battista DR, Bruehlman R, Sereika SS, Thase ME, DunbarJacob J. Beliefs about antidepressant medications in primary care patients: relationship to self-reported adherence. Med Care. 2005;43(12): $1203-1207$.

42. Ho SC, Jacob SA, Tangiisuran B. Barriers and facilitators of adherence to antidepressants among outpatients with major depressive disorder: A qualitative study. PLoS One. 2017;12(6):e0179290.

43. Hung CI, Wang SJ, Liu CY, Hsu SC, Yang CH. Comorbidities and factors related to discontinuation of pharmacotherapy among outpatients with major depressive disorder. Compr Psychiatry. 2011;52(4):370-377.

44. Samples H, Mojtabai R. Antidepressant self-discontinuation: results from the collaborative psychiatric epidemiology surveys. Psychiatr Serv. 2015;66(5):455-462.

45. van Geffen EC, Hermsen JH, Heerdink ER, Egberts AC, VerbeekHeida PM, van Hulten R. The decision to continue or discontinue treatment: experiences and beliefs of users of selective serotonin-reuptake inhibitors in the initial months - a qualitative study. Res Social Adm Pharm. 2011;7(2):134-150.

46. Goethe JW, Woolley SB, Cardoni AA, Woznicki BA, Piez DA. Selective serotonin reuptake inhibitor discontinuation: side effects and other factors that influence medication adherence. J Clin Psychopharmacol. 2007;27(5):451-458.

47. Novick D, Montgomery W, Moneta V, Peng X, Brugnoli R, Haro JM. Antidepressant medication treatment patterns in Asian patients with major depressive disorder. Patient Prefer Adherence. 2015;9: 421-428.

48. Leydon GM, Rodgers L, Kendrick T. A qualitative study of patient views on discontinuing long-term selective serotonin reuptake inhibitors. Fam Pract. 2007;24(6):570-575.

49. Zivin K, Kales HC. Adherence to depression treatment in older adults: a narrative review. Drugs Aging. 2008;25(7):559-571.

50. Sirey JA, BruceML, Alexopoulos GS, PerlickDA, Friedman SJ, Meyers BS. Stigma as a barrier to recovery: Perceived stigma and patient-rated severity of illness as predictors of antidepressant drug adherence. Psychiatr Serv. 2001;52(12):1615-1620.

51. Prins MA, Verhaak PF, Bensing JM, van der Meer K. Health beliefs and perceived need for mental health care of anxiety and depression - the patients' perspective explored. Clin Psychol Rev. 2008; 28(6):1038-1058.

52. Woodall A, Morgan C, Sloan C, Howard L. Barriers to participation in mental health research: are there specific gender, ethnicity and agerelated barriers? BMC Psychiatry. 2010;10:103. 


\section{Supplementary material}

Table SI Index of the terms used in this study, in relation to influencing factors

\begin{tabular}{|c|c|}
\hline Influencing factors & Definition in the study \\
\hline \multicolumn{2}{|l|}{ Positive factors } \\
\hline $\begin{array}{l}\text { Education about antidepressant } \\
\text { treatment }\end{array}$ & $\begin{array}{l}\text { Patient's knowledge about the use of antidepressant medicines in depression treatment, including } \\
\text { health literacy. }\end{array}$ \\
\hline Willingness to follow doctor's order & $\begin{array}{l}\text { Willingness and ability to follow doctor's order pertaining to the use of antidepressant medicines } \\
\text { in treatment of depression. }\end{array}$ \\
\hline Acceptance of depression diagnosis & Acceptance that one has a diagnosis of depression. \\
\hline Recognition of antidepressant medicine & $\begin{array}{l}\text { The recognition of the importance of antidepressant medicines in the treatment of unipolar } \\
\text { depression. }\end{array}$ \\
\hline $\begin{array}{l}\text { Positive effects of antidepressant } \\
\text { treatment }\end{array}$ & $\begin{array}{l}\text { Experiencing or beliefs about experiencing positive effects form the use of antidepressant } \\
\text { medicines, such as, the effectiveness of antidepressant, clinical improvement, recovery, feeling } \\
\text { better, few or no ADRs, and the observation of positive treatment outcomes from family } \\
\text { members and/or friends. }\end{array}$ \\
\hline Self-motivation & $\begin{array}{l}\text { The reliance on one's own powers and resources rather than those of others. This includes a } \\
\text { desire to feel better and achieve better clinical outcomes as well as self-reliance. }\end{array}$ \\
\hline Self-management & $\begin{array}{l}\text { The management of oneself pertaining to the consumption of antidepressant medicines; the } \\
\text { taking of responsibility for regular consumption. This includes routines for taking antidepressant } \\
\text { medicines, use of reminders or alarms, pill box, Webster-pak }{ }^{\circledR} \text {, diary etc. }\end{array}$ \\
\hline \multicolumn{2}{|l|}{ Negative factors } \\
\hline Unwillingness to rely on medicine & The reluctance to use antidepressant medicines. \\
\hline Denial of depression diagnosis & Belief that one does not have depression. \\
\hline $\begin{array}{l}\text { Denial of the need for antidepressant } \\
\text { treatment }\end{array}$ & Belief that one does not need an antidepressant medicine for treatment of depression. \\
\hline Disorganized life & $\begin{array}{l}\text { Relevant factors pertaining to everyday living that negatively influence medication adherence such } \\
\text { as running out of antidepressant medicine, excessive alcohol consumption, illicit substance use, etc. }\end{array}$ \\
\hline $\begin{array}{l}\text { Concern about long-term } \\
\text { antidepressant treatment }\end{array}$ & $\begin{array}{l}\text { Negative thoughts and concerns about long-term use of antidepressant medicines including fear of } \\
\text { addiction, interference with natural functions of the brain or body, etc. }\end{array}$ \\
\hline Self-stigma & $\begin{array}{l}\text { The process of an individual accepting society's negative evaluation and incorporating it into his or } \\
\text { her own personal value system and sense of self.' }\end{array}$ \\
\hline $\begin{array}{l}\text { Negative effects of antidepressant } \\
\text { therapy }\end{array}$ & $\begin{array}{l}\text { Experience or beliefs about experiencing negative effects from the use of antidepressant } \\
\text { medicines; including ineffective antidepressant treatment, feeling worse, unsatisfactory treatment } \\
\text { outcome, the existence of depressive symptoms, etc. }\end{array}$ \\
\hline Trial cessation of antidepressant & $\begin{array}{l}\text { Personal experiment to cease antidepressant medicine without the guidance of health } \\
\text { practitioners. }\end{array}$ \\
\hline
\end{tabular}

Abbreviation: ADR, adverse drug reaction.

\section{Reference}

1. Livingston JD, Boyd JE. Correlates and consequences of internalized stigma for people living with mental illness: a systematic review and meta-analysis. Soc Sci Med. 2010;71(12):2150-2161.

\section{Publish your work in this journal}

Patient Preference and Adherence is an international, peer-reviewed, open access journal that focuses on the growing importance of patient preference and adherence throughout the therapeutic continuum. Patient satisfaction, acceptability, quality of life, compliance, persistence and their role in developing new therapeutic modalities and compounds to optimize

\section{Dovepress}

clinical outcomes for existing disease states are major areas of interest for the journal. This journal has been accepted for indexing on PubMed Central. The manuscript management system is completely online and includes a very quick and fair peer-review system, which is all easy to use. Visit http://www dovepress.com/testimonials.php to read real quotes from published authors. 